\title{
Solar Radiation Prediction using Artificial Neural Network
}

\author{
S. Shanmuga Priya, Ph.D \\ Associate Professor \\ Dept. of Chemical Engineering \\ MIT, Manipal University Manipal, Karnataka
}

\author{
Mohammad Hashif Iqbal \\ PG Scholar \\ Dept. of Chemical Engineering \\ MIT, Manipal University, Manipal, Karnataka
}

\begin{abstract}
It is very important to analyze the influence of solar radiation for most of the application in solar energy research. Despite the great importance of Global Solar Radiation (GSR), the number of radiation stations are very less when compared to the stations that collect regular meteorological data like air temperature and humidity. The main objective of this paper is to study the feasibility of an Artificial Neural Network (ANN) based method to estimate and predict GSR. The studies shows that prediction using ANN are more accurate when compared to conventional models. The accuracy of prediction depends on input parameter combinations and training algorithm. The places that were selected for study was Bangalore, Thiruvananthapuram, Chennai and Hyderabad. Average temperature, maximum temperature, minimum temperature, and altitude were used as the input parameters. The ANN model was developed using ANN fitting tool (nftool) which consists of a standard two layers feed forward neural network trained with Lavenberg-Marquardt (LM) algorithm.
\end{abstract}

\section{General Terms}

Neurons, humidity, temperature, pressure.

\section{Keywords}

Artificial Neural Network, Solar Radiation, Mean Absolute Percentage Error.

\section{INTRODUCTION}

Solar radiation data is an important parameter in most of the solar energy research. Due to the industrial revolution that took place in the recent years, global warming has become one of the major issue. In this event, renewable energy resources, particularly, solar energy is being seriously considered to overcome the associated climatic changes. Almost all renewable energy resource derives their energy from sun. Solar energy has vast application in the field of agriculture, water heating, ventilation, heating and cooling, cooking and electricity production. This has led the research and development activities in this field. Plants growth rate is directly proportional to the amount of solar radiation received assuming other environmental parameters are not limiting. Generally solar radiation is measured using solar radiation components like pyranometer, pyrheliometer, sunshine duration meter etc. But due to the high cost, it is difficult to install these equipment's in each location. Moreover, due to the lack of accuracy of the instruments, missing data have been found. Here comes the importance of estimation and prediction of solar radiation using various models. Both conventional and Artificial Neural Network (ANN) based model have been developed for this purpose. Linear modeling of global solar energy, non linear modeling of global solar energy, modeling of global solar energy using fuzzy logic are some of the conventional methods used.ANN analysis works on the principle of human brain where in the processing of information is accomplished by a parallel distributed structure called neural network [1]. It has three layers, an input layer that receives data, an output layer that sends computed information, and hidden neurons that connects input and output layer. ANN techniques have been used for prediction due to the lack of accuracy of conventional or empirical models as ANN gives better results [2-5].

Different geographical and meteorological variables of a specific location can be used as ANN inputs for the prediction of solar radiation.

Mohandes et al. [6] predicted the global solar radiation as a function of latitude, longitude, altitude and sunshine duration in Saudia Arabia. In testing stations MAPE changes from 6.5 to 19.1 .

AI-Alawi and AI-Hinai [7] studied multi layer feed forward network, back propagation (BP) training algorithm for global radiation prediction in Seeb which uses inputs like location, month, mean temperature, mean pressure, mean vapor pressure, mean relative humidity, mean sun shine hours and mean wind speed. The MAPE varies from 5.43 to 7.30.

Rehman and Mohandes [8] studied four combinations of input parameters, day, maximum air temperature, mean air temperature, and relative humidity to estimate diffuse solar radiation for Abha city in Saudi Arabia. It was found that using relative humidity and daily mean temperature gives better results than other combinations with mean square error (MSE) of $5.18 \times 10^{-7}$.

Azeez [9] used Feed forward back propagation Neural Network for monthly estimation of average global solar radiation in Gusau, Nigeria. The sunshine duration, maximum ambient temperature and relative humidity are taken as input and solar radiation as output. The statistical analysis $(\mathrm{R}=99.96$, MPE $=0.8512$, RMSE $=0.0028)$ has shown good agreement between the estimated and measured values of global solar radiation.

Korachagaonet.al[10] considered the estimation of solar radiation as the most important parameter for the design and development of various solar energy systems. The foremostobjective of the present study was to estimate the monthly average global solar radiation Iranna- Bapat's model is developed to estimate the value of global solar radiation at any location on earth surface. This model uses the most commonly measurable meteorological parameters such as ambient temperature, humidity, wind-speed, moisture for a given location. The computed values from Iranna-Bapat's model are compared with the measured values. Iranna-Bapat's model demonstrated acceptable results, and statistically displayed lower RMSE $(<10 \%)$. Therefore this model could be a good estimator for predicting the global solar radiation at 
other locations for Chinese province, where such data is not available.

GayathriVijayakumaret.al[11] found that solar radiation data are available for many locations on an hourly basis. Simulation studies of solar energy systems have generally used these hourly values to estimate long-term annual performance, although solar radiation can exhibit wide variations during an hour. The inaccuracies are determined by examination of the frequency distribution and diffuse fraction relationships for short-term solar radiation data as compared to existing regressions and by comparing calculated radiation on tilted surfaces and utilizability based on hourly and shortterm radiation data.

Table 1. Input variables used in ANN based solar prediction

\begin{tabular}{|c|c|c|c|}
\hline Reference & $\begin{array}{l}\text { ANN input } \\
\text { variable }\end{array}$ & $\begin{array}{c}\text { Prediction } \\
\text { accuracy }\end{array}$ & Location \\
\hline $\begin{array}{l}\text { Khatib et al. } \\
\text { [12] }\end{array}$ & $\begin{array}{l}\text { Day's } \\
\text { number, } \\
\text { sunshine } \\
\text { ratio, latitude } \\
\text { and } \\
\text { longitude }\end{array}$ & $\begin{array}{l}\text { MAPE for } \\
\text { global and } \\
\text { diffuse } \\
\text { radiation are } \\
7.96 \%, 9.8 \% \\
\text { respectively }\end{array}$ & Malaysia \\
\hline $\begin{array}{l}\text { Alam et al } \\
{[13]}\end{array}$ & $\begin{array}{l}\text { Latitude, } \\
\text { longitude, } \\
\text { month of the } \\
\text { year, } \\
\text { altitude, } \\
\text { rainfall ratio, } \\
\text { relative } \\
\text { humidity and } \\
\text { mean } \\
\text { duration of } \\
\text { sunshine per } \\
\text { hour }\end{array}$ & $\begin{array}{l}\text { RMSE varies } \\
\text { from } 1.65 \text { to } \\
2.79 \%\end{array}$ & India \\
\hline $\begin{array}{l}\text { Mubiru and } \\
\text { Banda [14] }\end{array}$ & $\begin{array}{l}\text { Cloud cover, } \\
\text { average } \\
\text { annual } \\
\text { sunshine } \\
\text { hours, } \\
\text { latitude, } \\
\text { longitude, } \\
\text { altitude and } \\
\text { rainfall }\end{array}$ & $\begin{array}{l}\text { MAPE and } \\
\mathrm{R}^{2} \text { are } 0.3 \\
\text { and } 97.4 \%\end{array}$ & Uganda \\
\hline Jiang Y [15] & $\begin{array}{l}\text { Mean } \\
\text { sunshine, } \\
\text { latitude and } \\
\text { altitude }\end{array}$ & $\begin{array}{l}\mathrm{R}^{2}=0.97 \\
\mathrm{RMSE}=1.4 \\
\mathrm{MJ} / \mathrm{m}^{2}\end{array}$ & China \\
\hline Fadare [16] & $\begin{array}{l}\text { Latitude, } \\
\text { longitude, } \\
\text { altitude, }\end{array}$ & $\begin{array}{l}\mathrm{R}^{2} \\
\text { training and } \\
\text { testing cities }\end{array}$ & $\begin{array}{l}195 \text { cities in } \\
\text { Nigeria }\end{array}$ \\
\hline
\end{tabular}

\begin{tabular}{|l|l|l|l|}
\hline & $\begin{array}{l}\text { month, mean } \\
\text { sunshine } \\
\text { duration, } \\
\text { relative and } \\
\text { mean } \\
\text { temperature. } \\
\text { than 90\% }\end{array}$ & \\
& & \\
\hline
\end{tabular}

\section{METHODOLOGY}

In the present study 4 Indian locations, Bangalore, Thiruvananthapuram, Chennai and Hyderabad are selected. The meteorological data that are selected for the analysis is average temperature $(T)$, maximum temperature $\left(T_{\max }\right)$, minimum temperature $\left(\mathrm{T}_{\min }\right)$ and altitude $(\mathrm{H})$ taken from National Aeronautics and Space Administration (NASA) [17]. The data's are shown in Table 2 . Monthly average daily solar radiation data $\left(\mathrm{kWh} / \mathrm{m}^{2} /\right.$ day $)$ is taken from Indian Meteorological Department (IMD) Pune compiled by Anna Mani [18].

Table 2. Meteorological data and geographical coordinates of selected cities

\begin{tabular}{|c|c|c|c|c|}
\hline City & $\mathrm{T}\left({ }^{\mathrm{o}} \mathrm{C}\right)$ & $\begin{array}{c}\mathrm{T}_{\max }\left({ }^{\mathrm{o}}\right. \\
\mathrm{C})\end{array}$ & $\mathrm{T}_{\min }\left({ }^{\circ} \mathrm{C}\right)$ & $\mathrm{H}(\mathrm{m})$ \\
\hline Bangalore & 24.7 & 27.5 & 21.9 & 897 \\
\hline Thiruvananthapuram & 26.9 & 27.6 & 26.2 & 64 \\
\hline Chennai & 27.7 & 30.1 & 25.1 & 6 \\
\hline Hyderabad & 27 & 31.7 & 23.2 & 536 \\
\hline
\end{tabular}

The ANN model is developed using artificial neural network fitting tool (nftool) of MATLAB 2010 software. It consists of a standard feed forward two-layered network which is trained with Lavenberg - Marquardt (LM) algorithm.

The data collected is randomly divided and $60 \%$ can be used for training, $20 \%$ for testing and $20 \%$ for validation. Testing data does not have any effect on training. It provides independent measure of network performance during and after training. The validation data is used for measuring generalized capability. The proposed algorithm is shown in Figure 2.

The data for cities Bangalore and Thiruvananthapuram are used for training data and the data for cities Chennai and Hyderabad are used for testing. The performance of the developed model is evaluated based on MAPE, a statistical error parameter. 


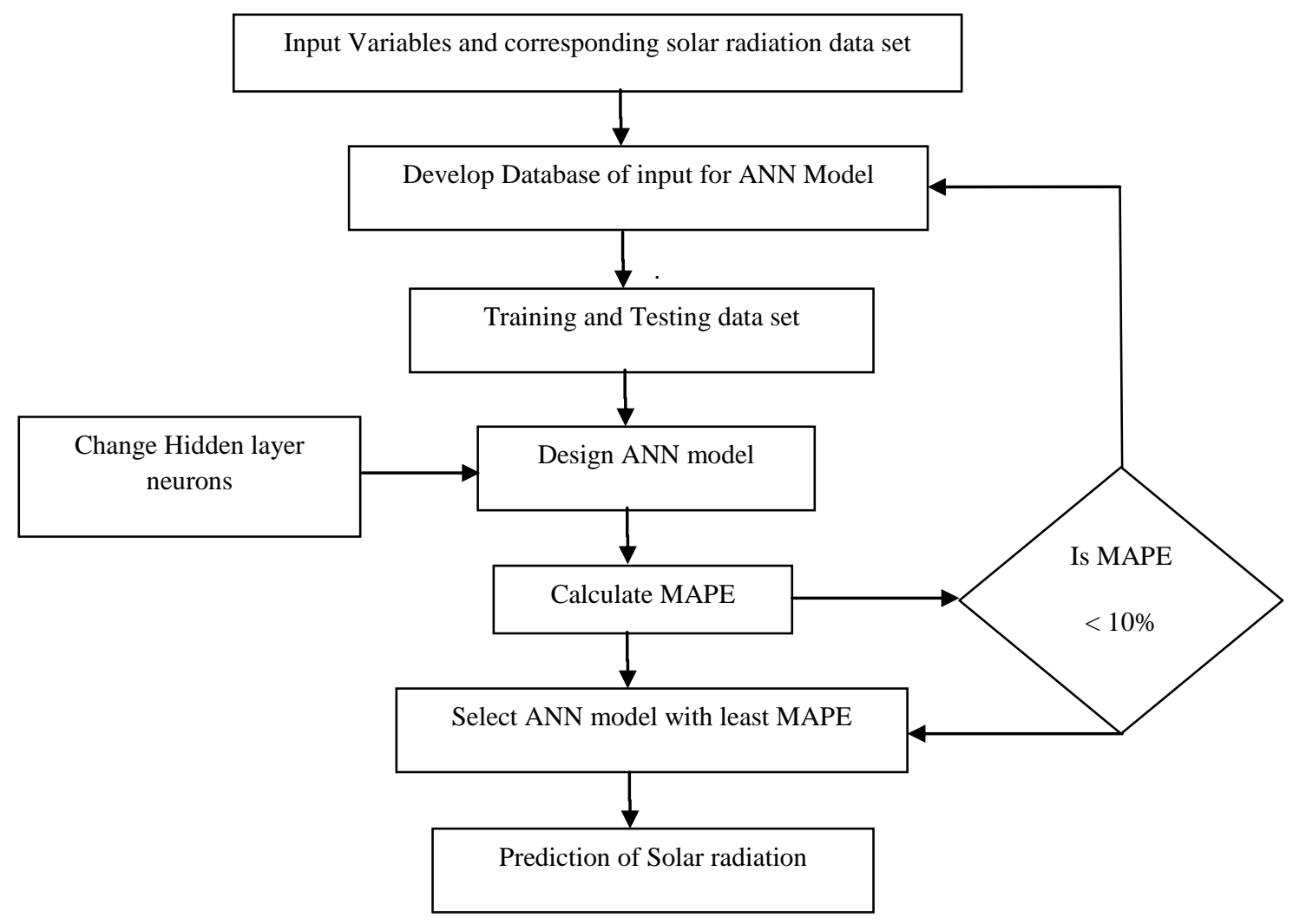

Fig1: Proposed algorithm for solar radiation prediction

$\mathrm{MAPE}=100 / \mathrm{n} \sum\left[\left(\mathrm{SR}_{\mathrm{ANN}}-\mathrm{SR}_{\mathrm{ACT}}\right) / \mathrm{SR}_{\mathrm{ACT}}\right]$

Where $\mathrm{SR}_{\mathrm{ANN}}=$ Predicted Solar Radiation

$$
\begin{aligned}
& \mathrm{SR}_{\mathrm{ACT}}=\text { Actual Solar Radiation } \\
& \mathrm{n}=\text { total number of observations. }
\end{aligned}
$$

ANN model with least MAPE is selected and used for prediction of solar radiation. The accuracy of prediction is evaluated by comparing the result with MAPE given by Lewis [19]. The MAPE less than $10 \%$ indicates high prediction accuracy.

\section{RESULTS AND DISCUSSION}

The performance plot is shown in Figure 2. In the plot, as number of epoch increases, the Mean Squared Error (MSE) decreases.The errors during validation and testing has similar characteristics. Epoch 14 has the best validation performance and no significant overlapping has occurred in this epoch.

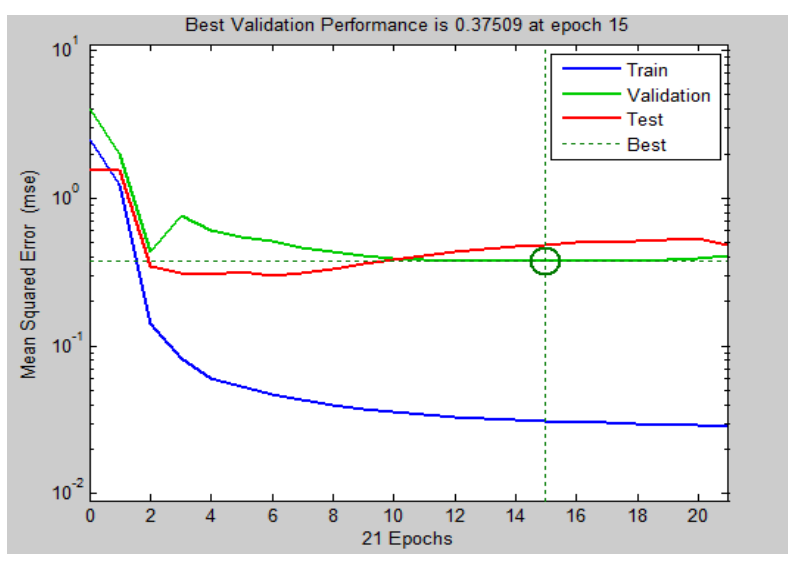

Fig 2: Performance plot

The regression plot (Figure 3 ) between output and target is the measure of how well the variation in the output is described by the target. The slope and intercept are 0.94 and 0.36 respectively. These value shows that the fit is good. The regression ( $\mathrm{R}$ value) is $88.62 \%$ for the total response. 


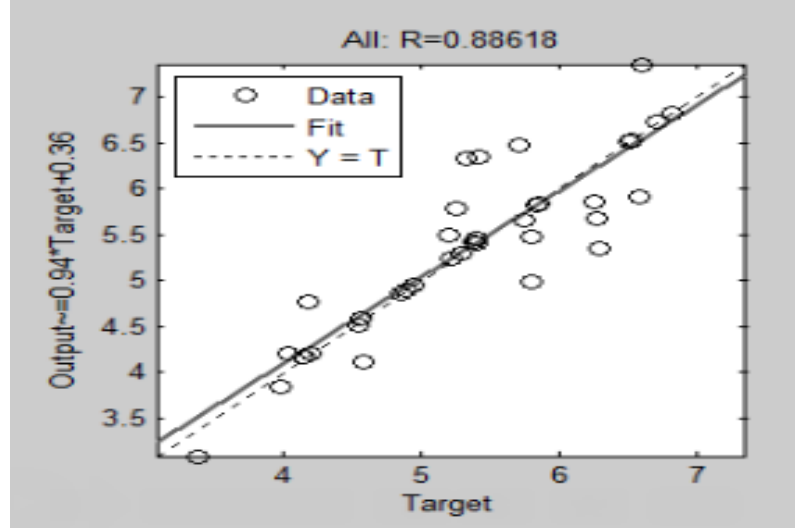

Fig 3: Regression plot

The MAPE for training stations Bangalore and Thiruvananthapuram was found to be $5.13 \%$ and $6.29 \%$ respectively. MAPE for testing stations, Chennai and Hyderabad, was $7.39 \%$ and $8.09 \%$ respectively.

\section{CONCLUSION}

The use of Artificial Neural Network technique in solar radiation modeling and prediction is done for 4 cities in India and studied. The study indicates that the proposed ANN model has lower MAPE. The model includes input parameters like average temperature, maximum temperature, minimum temperature and altitude and output as solar radiation. A comparison with the proposed data with the measured data shows that the model is in good agreement with the IMD measured data. This model will be suitable for predicting solar radiation for other locations in India and can be used for solar energy applications.

There is a lot of scope for future study in this area. During the ANN simulation, hidden layer neurons has to be changed one by one and MAPE has to be evaluated which is time consuming. A method has to be developed to find out the suitable number of neurons in the hidden layer. Comparison of different ANN models has to be done so as to identify the best model. A future research has to be done to find out the most relevant input parameter from meteorological variables with better prediction accuracy.

\section{ACKNOWLEDGEMENTS}

The authors wish to express their earnest gratitude to Manipal University, Manipal for providing all the facilities required for carrying out this project. The authors would also like to thank Associate Director, Innovation Centre for providing the solar energy radiation equipments in the solar laboratory.

\section{REFERENCES}

[1] ND Kaushika, RK Tomar, SC Kaushik. Artificial Neural Network model based on interrelationship of direct, diffuse and global solar radiations. Solar Energy. 2014, 327-342.

[2] Khatib T, Mohammed A, Sopian K. A review of solar energy modeling techniques. Renew Sustain Energy. 2012, 16:2864-9.

[3] Senkal O, Kuleli T. Estimation of solar radiation over Turkey using artificial neural network and satellite data. Appl Energy. 2009, 86:1222-8.
[4] Mubiru J, Banda EJKB. Estimation of monthly average daily global solar irradiation using artificial neural networks. Sol Energy. 2008, 82:181-7.

[5] Jiang Y. Prediction of monthly mean daily diffuse solar radiation using artificial neural networks and comparison with other empirical models. Energy Policy. 2008, 36:3833-7.

[6] Mohandes M, Rehman S, Halawani TO. Estimation of global solar radiation using artificial neural networks. Renew Energy. 1998, 14(1-4):179-84.

[7] Al-Alawi SM, Al-Hinai HA. An ANN based approach for predicting global radiationin locations with no direct measurement instrumentation. Renew Energy. 1998, 14(1-4):199-204.

[8] Rehman S, Mohandes M. Estimation of diffuse fraction of global solar radiation using artificial neural networks. Energy Sources.2009, 31:974-84.

[9] Azeez MAA. Artificial neural network estimation of global solar radiation using meteorological parameters in Gusau, Nigeriaa, Arch. ApplSci Res. 2011, 3(2):586-95.

[10] KorachagaonIranna, Bapat VN. Generalized siteindependent models for estimating global solar radiation for Asia \& Africa. International Journal of Emerging Technologies and Applications in Engineering, Technology and Science, IJ-ETA-ETS. 2009, 2(2):250256.

[11] GayathriVijayakumar, Michael Kummert, Sanford A Klein, Willaiam A. Beckman. Analysis of short term solar radiation data. Solar Energy. 2005, 79(5): 495-504.

[12] Khatib T, Mohamed A, Sopian K, Mahmoud M. Solar energy prediction for Malaysia using artificial neural networks. Int J Photoenergy. $2012,1-16$.

[13] Alam S, Kaushik S C, Garg S N. Computation of beam solar radiation at normal incidence using artificial neural network. Renew Energy. 2006, 31:1483-91.

[14] Mubiru J, Banda EJKB. Estimation of monthly average daily global solar irradiation using artificial neural networks. Sol Energy. 2008, 82:181-187.

[15] Fadare DA. Modeling of solar energy potential in Nigeria using an anrtificial neural network model. Appl Energy. 2009, 86:1410-22.

[16] Jiang Y. Computation of monthly mean daily global solar radiation in China using artificial neural networks and comparison with other empirical models. Energy 2009, 34:1276-83.

[17] https://eosweb.larc.nasa.gov Atmospheric Science Data Centre, NASA, USA.

[18] Mani A. Handbook of solar radiation data for India. New Delhi: Allied Publishers Pvt. Ltd; 1981.

[19] Lewis CD. International and business forecasting methods. London : Butterworths; 1982. 